\title{
Jerneja KAVČIČ $\mid$ NAGLASNI PROBLEMI STARE IN MODERNE GRŠČINE
}

\section{Abstract}

The subject of the article are the accentual features of ancient and modern Greek. The first part discusses the problems of the position of the Greek accent at the earliest stages of development and the accentual rules of Ionic-Attic, Lesbic and Doric dialect. The second and the third part present the questions of the phonetics of the ancient Greek accent and the process in which the modern Greek accent appeared.

\section{Izvleček}

C̆lanek obravnava značilnosti starogrškega in novogrškega naglasa. Prvi del obravnava probleme naglasnega mesta grškega naglasa v najstarejših obdobjih razvoja in naglasna pravila v jonsko-atiškem, lesboškem in dorskem narečju. V drugem in tretjem delu so predstavljena vprašanja fonetike starogrškega naglasa in proces, v katerem se je oblikoval modernogrški naglas.

Kot kaže več znamenj', je bil naglas v stari grščini tonemski. Mesto in vrsta naglasa sta bila odvisna od več pravil. Temeljno pravilo, ki je za mesto naglasa veljalo v vseh grških narečjih, za katere je na razpolago kaj več podatkov o naglasu, to je v jonsko-atiškem, lesboškem in dorskem, je bilo naslednje: mesto in vrsta naglasa sta odvisna od dolžine samoglasnika v zadnjem zlogu besede; če je kratek, akut ne sme seči preko predpredzadnjega zloga in cirkumfleks preko predzadnjega, in če je zadnji samoglasnik dolg, akut ne sme seči preko predzadnjega zloga, s cirkumfleksom pa je lahko naglašen samo zadnji zlog besede. Po tem pravilu je bil torej v grščini lahko naglašen samo eden izmed zadnjih treh zlogov besede. Obstajalo je tudi pravilo, da mora biti predzadnji zlog, če vsebuje dolg samoglasnik in je naglašen, nujno naglašen s cirkumfleksom, če je samoglasnik v zadnjem zlogu kratek. Toda poznalo je precej izjem. V literarnih delih, ki so napisana v književnem dorskem narečju, so namreč izpričani primeri kot $\gamma v v \alpha i k \varepsilon \varsigma^{2}$.

Kar se tiče naglasnega mesta, je bilo torej splošno grško lahko samo prvo pravilo. $V$ zvezi $z$ razlikovanjem med osnovnima naglasnima različica-

1 Viri za naglas so poročila grških slovničarjev in drugih piscev (najstarejše je Platonovo), grške jezikovne značilnosti in nekateri glasbeni zapisi.

${ }^{2}$ Prim. Schwyzer, str. 384 
ma, akutom in cirkumfleksom, pa je v vseh narečjih veljalo tudi, da je s cirkumfleksom lahko naglašen samo dolg samoglasnik, medtem ko so bili $\mathrm{z}$ akutom lahko naglašeni tudi kratki samoglasniki.

Ta pravila so torej najstarejša in so veljala že za skupno grščino. O njihovi starosti ne priča le dejstvo, da so kasneje obstajala tako v jonskoatiškem in lesboškem kot $\mathrm{v}$ dorskem narečju, ampak tudi nekatere »izjeme « iz klasične dobe. Pravilo, da je predpredzadnji zlog naglašen samo, kadar je zadnji samoglasnik kratek, je gotovo starejše od prestavitve dolžine in samoglasniškega krčenja. Oblike kot $\pi \delta ́ \lambda \varepsilon \omega \zeta$ so s stališča kasnejših dob izjemne, ker so splošno grška naglasna pravila začela delovati prej kot

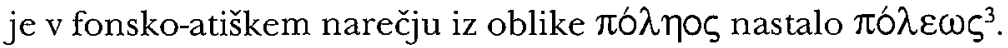

\section{Grški in indoevropski naglas}

Koje v grščini začelo veljati pravilo, da mora biti naglašen eden izmed zadnjih treh zlogov v besedi, se je mesto naglasa pogosto spremenilo. Če se je stari naglas ujemal z novimi pravili, je načeloma ostal, na primer $v$

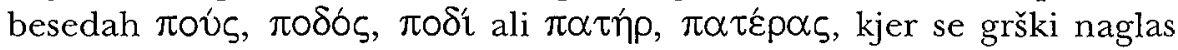
ujema z naglasom $v$ Vedah: pát, padás, padíoz. pitá, pitâras ${ }^{4}$. V nasprotnem primeru se je naglas prestavil na zadnje mesto, ki ga naglasna pravila še dopuščajo (prim. ved. bhâramānas: gr. фepó $\mu \varepsilon v o \varsigma)^{4}$.

Poseben primer predstavljajo osebne glagolske oblike ${ }^{5}$, ki so bile v indoevropščini, vsaj v zadnji fazi, domnevoma lahko enklitične ali naglašene. To je značilno za glagol v Vedah, kjer so osebne glagolske oblike enklitične v glavnih in neodvisnih stavkih (Wackernaglov zakon). Če je bilo takšno tudi izhodiščno stanje za grščino, so enklitične oblike po pravilu, da mora biti naglašen eden izmed zadnjih treh zlogov v besedi, dobile naglas na mestu, ki je bil tako daleč od konca besede, kot so dopuščala naglasna

${ }^{3}$ Oblika $\pi o ́ \lambda \varepsilon \omega \nu$ naj bi nastala po analogiji, Sihler, str. 75.

${ }^{4}$ Sihler, str. 236

5 Za neosebne glagolske oblike veljajo splošna načela, praviloma so torej ohranjale stari naglas, ki se je v prezentovih oblikah ravnal po drugačnih pravilih kot v aoristovih. V tematni spregatvi so bile prezentove oblike naglašene na zlogu pred veznim samoglasnikom $(\lambda \alpha \mu \beta \alpha v \varepsilon \iota \nu, \lambda \alpha \mu \beta \alpha \nu \omega \nu)$, v aoristu pa na veznem samoglasniku

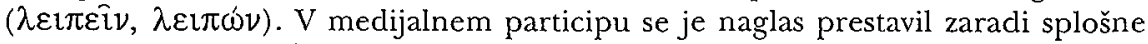

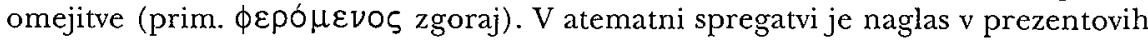
in aoristovih oblikah praviloma na zlogu pred znamenjem za particip ali infinitiv

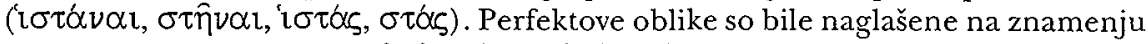

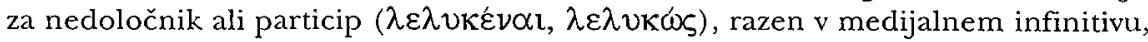
ki je bil naglašen na predhodnem zlogu $(\lambda \varepsilon \lambda \hat{v} \sigma \vartheta \alpha \mathrm{l})$. V infinitivu in participu fu-

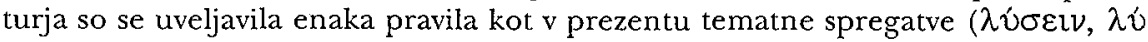
$\sigma \omega v)$, prim. Chantraine, str. 314, 15. 
pravila. Temu procesu so se izognile nekatere dvozložne prezentove obli-

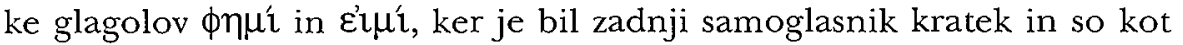
take lahko tvorile konec naglasne enote; oba glagola sta bila tudi zelo pogosto rabljena, takšne oblike pa so praviloma najbolj konzervativne.

Ob takem razvoju so morale na novo naglašene oblike prevladati nad starimi naglašenimi glagoli. V grščini je namreč ostalo bolj malo sledi za starejšimi oblikami, na primer za tistimi, ki so bile naglašene na zadnjem zlogu, in so izpričane v Vedah. Naglas pri osebnih glagolskih oblikah je praviloma pomaknjen čimbolj proti začetku besede. Med izjeme spada pet imperativov krepkega aktivnega aorista ( $\varepsilon^{\prime} \imath \pi \dot{\varepsilon}, \dot{\varepsilon} \lambda \vartheta \dot{\varepsilon}, ' \imath \delta \dot{\varepsilon}, \varepsilon \dot{v} \rho \dot{\varepsilon}, \lambda \alpha \beta \dot{\varepsilon}$ ) in medijalni imperativi krepkega aorista ( $\gamma \varepsilon v \circ \hat{v}, \lambda \alpha \beta \circ \hat{v}$ itd.). $V$ teh primerih gre za stari indoevropski način naglaševanja, ki je bil pri osebnih glagolskih oblikah enak kot pri neosebnih (prim. op. 5). Druga skupina izjem so glagoli $z$ dvema predponama, kjer je naglašena prva predpona od konca besede ( $\sigma \cup \mu \pi \rho o ́ \varepsilon \varsigma)$, čeprav bi bil po splošnih naglasnih pravilih naglas lahko na začetku besede. Za predpono je veljal tudi avgment, zato

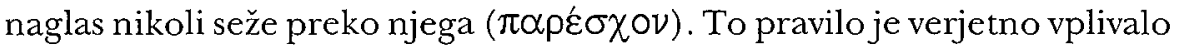
tudi na naglaševanje sestavljenk enozložnih oblik, ki so naglašene na pred-

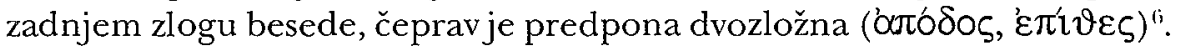
Med tovrstne izjeme ne spadajo oblike, ki so nastale po krčenju, npr. $\tau \mu \mu \hat{\alpha}, 5$,

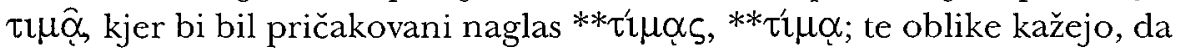
so grška naglasna pravila začela delovati prej, kot je prišlo do samoglasniškega krčenja.

Obstaja še nekaj drugih zakonitosti, po katerih se je spremenil sistem prostega naglaševanja, kakršnega je poznala indoevropščina. Najtrdnejše pravilo je ti. zakon o naglasu na dolgem predzadnjem samoglasniku. Kot reče-

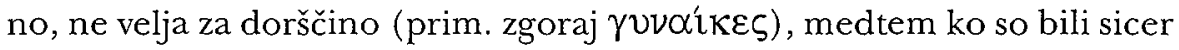
v grščini dolgi samoglasniki v predzadnjem zlogu naglašeni s cirkumfleksom, če je bil zadnji samoglasnik v besedi kratek. V narečjih, kjer je zakonitost delovala, je na tem mestu nastal cirkumfleks, tudi kadar je bil prvotni naglas drugačen ${ }^{7}$. Tak primer je beseda $\chi \rho \eta \hat{\mu \alpha}$, ki je bila prej naglašena $\mathrm{z}$ akutom, o čemer priča oblika $\chi \rho \eta$.

Med ostalimi mlajšimi pojavi sta vjonsko-atiškem narečju pomembnejša dva zakona, Wheelerjev in Vendryesov. Po prvem zakonu je v besedah $\mathrm{z}$ daktilsko zgradbo, ki so bile naglašene na zadnjem zlogu, naglas na predzadnjem zlogu: ${ }^{*} \pi 0 \imath \kappa \imath \lambda o ́ \varsigma>\pi 0 \imath \kappa i ́ \lambda o \varsigma:$ stind. pesalá, medtem ko so pridevniki

"Chantraine, str. 317; toda ni jasno, zakaj v sestavljenkah z dvema predponama naglas ne more biti na začetku besede. Schwyzer (str. 391) navaja drugačno razlago, po kateri so oblike kot $\varepsilon \pi i v \varepsilon \zeta, ~ \measuredangle \pi \delta \delta o \zeta ~ i n ~ \sigma \nu \mu \pi \rho o ́ \varepsilon \varsigma$ nastale pri enklizi (ker je enklitika, v tem primeru osebna glagolska oblika, prestavila naglas na predhodni zlog).

7 Kako je bilo s cirkumfleksom v indoevropščini, ni povsem jasno. Morda je nastal šele znotraj grščine, prim. Sihler str. 237. 
na isto pripono, toda $\mathrm{z}$ drugačno ritmično zgradbo, naglas obdržali na

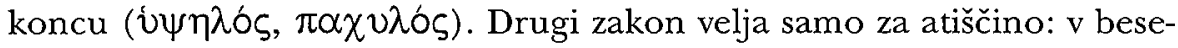
dah z ritmično zgradbo kretika, ki so bile naglašene na predzadnjem zlogu, se je naglas prestavil na predpredzadnji zlog. Ta zakon je začel delovati precej pozno, saj so v klasični dobi še izpričane stare oblike poleg mlajših

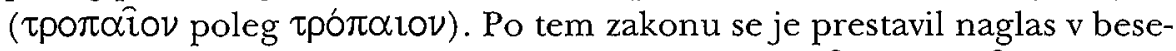

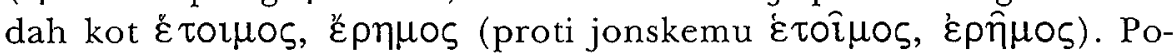
sebnost obeh zakonov je, da se naglas ne ravna po dolžini samoglasnika, temveč po kvantiteti zloga. Oba izražata težnjo, da bi se naglas pomaknil čim bolj proti začetku besede.

Ta težnja je sicer najbolj značilna za lesboško narečje. Kot poročajo grški slovničarji, je bil v lesboščini naglas recesiven v vseh besednih vrstah in se je v podobnih primerih prestavil proti začetku besede toliko, kolikor

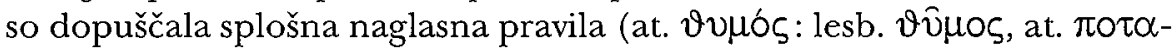
$\mu o ́ \varsigma: ~ l e s b . \pi \delta ́ \tau \alpha \mu \circ)$ ). Slovničarji pojavu pravijo baritoneza ( $\beta \alpha \rho \nu \tau o ́ v \eta \sigma \iota \varsigma)$.

Naglas se je spremenil tudi v dorščini, kjer se je v večini primerov v primerjavi z jonsko-atiškim narečjem prestavil za eno ali dve mori proti koncu besede $e^{8}$. Dorski naglas torej kaže nasprotno težnjo od jonsko-atiškega in lesboškega narečja.

\section{Fonetična plat naglasa v stari grščini}

Medtem ko je stanje pri naglasnem mestu jasno, predstavlja več težav fonetična plat grškega naglasa. Že razlika med osnovnima različicama, aku-

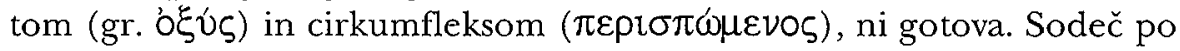
poročilih grških slovničarjev, ki so uvedli tudi pravopisna znamenja ${ }^{9}$, je razlika med akutom in cirkumfleksom obstajala v tonskem poteku. Pri akutu ali rastočem naglasu naj bi tonska višina vseskozi naraščala in dosegla najvišjo točko na koncu naglašenega zloga, medtem ko bi pri cirkumfleksu ali rastoče-padajočem naglasu najvišjo točko dosegla na začetku naglašenega zloga in nato upadala. Takšna razlika med osnovnima načinoma tonemskega naglaševanja je nekoliko nenavadna; bolj običajno bi bilo razlikovanje med rastočim in padajočim naglasom. Toda v njen prid po drugi strani govori tudi nekaj jezikovnih pojavov, na primer zgoraj navedeno pravilo,

${ }^{8}$ Schwyzer, str. 382. Takšna razlaga velja, če predpostavljamo, da sta se akut in cirkumfleks razlikovala po tonskem poteku (prim. Fonetična plat naglasa v stari grščini): kratek samoglasnik je dolg eno moro in dolg samoglasnik dve mori; akut lahko ob takšni razlagi razložimo kot naglas na kratkem samoglasniku ali na drugi mori dolgega samoglasnika, cirkumfleks pa kot naglas na prvi mori dolgega samoglasnika.

9 Okrog 1. 200 pr. Kr. so jih uvedli aleksandrinski filologi. 
da je s cirkumfleksom lahko naglašen samo dolg samoglasnik ${ }^{10}$. Akut in cirkumfleks je vseeno možno razlagati drugače kot ju razlagajo grški slovničarji, ki so večinoma živeli v času, ko grški naglas že davno ni bil več tonemski, torej kot rastoč in padajoč naglas ${ }^{11}$.

Dodatne težave predstavlja znamenje za gravis ( $\beta \alpha \rho u ́ \zeta)$, ki se v pravopisu, ki je še danes v rabi v izdajah starogrških tekstov (bizantinski pravopis), uporablja kot različica akuta: stoji namesto akuta na zadnjem zlogu razen pred premorom. Toda to pravopisno pravilo se je uveljavilo šele ob koncu antike, ko je bil grški naglas gotovo že dinamičen. Okrog leta 400 po Kr. ga je uvedel Teodozij iz Aleksandrije. Bistvena razlika v primerjavi s prejšnjim aleksandrinskim pravopisom je prav v rabi znamenja za gravis. Kot poročajo grški slovničarji, so prej to znamenje pisali sploh na vsak zlog, ki ni nosil akuta ali cirkumfleksa. Tak pravopis dejansko izpričujejo neka-

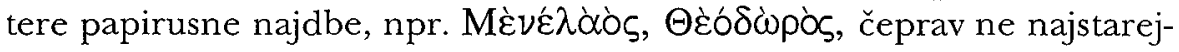
$\check{s}^{12}$. Na starejših so besede, ki so naglašene $z$ akutom na zadnjem zlogu, sredi stavka največkrat označene $z$ gravisom na predzadnjem zlogu, daljše besede pa imajo to znamenje pogosto tudi na ostalih nenaglašenih zlogih.

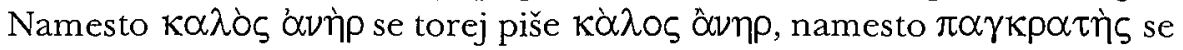

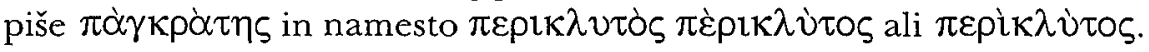

Pravopisne spremembe razlago gravisa zgolj otežujejo. Danes ni enotnega mnenja, kaj naj bi znamenje predstavljalo. Po prvi razlagi (prim. Schwyzer, str. 374) so bizantinska pravopisna pravila posledica napačnega razumevanja prejšnjega pravopisa in nimajo nobene zveze s fonetično platjo grškega naglasa. Druga pravopisna sprememba, do katere je prišlo v pozni antiki, je bila namreč ta, da so se znamenja za naglas in pridih na diftongih prestavila proti desni. Na enak način naj bi se gravis ob (napačni) predpostavki, da je bil zadnji zlog nenaglašen, ker se je praviloma pisal brez naglasnega znamenja, s predzadnjega zloga prestavil na zadnjega. Po tej razlagi so se vse besede, ki so bile naglašene $\mathrm{z}$ akutom na zadnjem zlogu, tudi sredi stavka izgovarjale enako kot sicer. Do tako mehanične prestavitve naglasnega znamenja bi toliko lažje prišlo zato, ker v 5. st. po Kr. grški naglas gotovo ni bil več tonemski (prim. spodaj).

Po drugi strani prav odsotnost akuta na zadnjem zlogu na starejših papirusnih najdbah lahko pomeni, da se je akut v tem okolju spremenil. Po starejšem pravopisu se akut na zadnjem zlogu ne le izpušča, ampak ga

\footnotetext{
${ }^{10}$ Drug tak primer je samoglasniško krčenje. Akut nastane, kadar je v neskrčeni obliki naglašen drugi samoglasnik ( $\left.\varepsilon \sigma \tau \alpha \omega \omega_{\zeta}>\dot{\varepsilon} \sigma \tau \omega_{\zeta}\right)$, cirkumfleks pa, kadar je naglas na prvem delu ( $\pi$ ol $\varepsilon \varepsilon \imath>\pi \circ \ell \varepsilon \hat{\imath}$ ). Na ta način je morda cirkumfleks nastal, prim. Sihler, str. 237.

"prim. Sihler, str. 235: "The actual PHONETIC difference was one of falling pitch ("circumflex") and rising pitch (»acute")."

${ }^{12}$ prim. Schwyzer, str. 374, Allen, Vox Graeca, str. 115
} 
že tedaj pogosto nadomešča gravis ${ }^{13}$. Toda ni gotovo, kako naj bi se akut spremenil, ker tudi pomen izraza gravis ( $\beta \alpha \rho u ́ \varsigma)$ ni povsem jasen. V zvezi z naglasom se pojavlja že pri Platonu in Aristotelu ${ }^{14}$, kjer bi se ga dalo razumeti kot nenaglašen zlog ali, še zlasti pri Aristotelu, kot padajoč naglas. Na ta način je najlaže razumeti tudi poševno znamenje $\backslash$ ki se je pod tem imenom uporabljalo v pravopisu za označevanje posameznih zlogov in prvotno za drugi (verjetno padajoči) del cirkumfleksa. Toda možen je

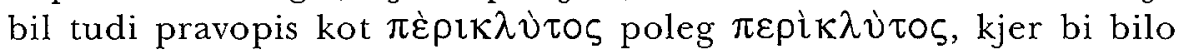
gravis lažje razumeti kot nenaglašen zlog. V tem primeru se zastavi vprašanje, zakaj so znamenje za gravis sploh uvedli. Toda grški pravopis je od samega začetka poznal tudi znamenje za šibki pridih, ki pomeni odsotnosti ostrega pridiha, podobno bi torej gravis pomenil odsotnost naglasa. Če je gravis nenaglašen zlog, bi bilo upravičeno tudi znamenje za cirkumfleks: za drugi del cirkumleksa je po razlagi grških slovničarjev, ki so uvedli tudi pravopisna znamenja, značilen prehod od najvišjega tona k najnižjemu (kar bi pomenil gravis), toda ta prehod je nujno postopen, zato ni bilo treba uvajati dodatnega znamenja za padajoči del cirkumfleksa.

Dionizij Halikarnaški ${ }^{15}$ označuje $z$ izrazom ßopús vse nenaglašene zloge in tudi drugi del cirkumfleksa. Na takšno pojmovanje kažejo tudi starejše pravopisne variante, kjer se gravis lahko uporablja tako za nenaglašene zloge kot za padajoči del cirkumfleksa. Videti je torej, da je izraz ßopú vsaj v aleksandrinski dobi in kasneje lahko pomenil tako nenaglašen zlog kot padajoč naglas. Bopúsje vsak zlog, ki ne nosi najvišjega tona v besedi, ali odsotnost rastočega naglasa. Toda takšna razlaga ne pove nič natančnejšega o tem, kako se je izgovarjal gravis, kadar je nadomestil akut. Tonska višine se je morala znižati, toda lahko se je izenačila $z$ nenaglašenim zlogom ali pa je akut prešel v padajoč naglas. Kot padajoč naglas je gravis smiselno razlagati zlasti, če predpostavljamo, da sta akut in cirkumfleks rastoč in rastoče-padajoč naglas.

\section{Razvoj v moderni grščini}

Tak način naglaševanja je v grščini obstajal do helenizma, ko so v Kotví najprej izginile narečne razlike in so prevladala naglasna pravila jonskoatiške narečne skupine ${ }^{16}$. Temeljna sprememba, ki jo je doživel grški naglas, pa je izguba tonemskega naglasa. Moderna grščina ima dinamičen.

\footnotetext{
13 Sturtevant, str. 101

${ }^{14}$ Platon, Cratyl. 399A, Aristotel, Poet. 1456b in Rhet. 1403b

${ }^{15}$ De compositione verborum 11

${ }^{16} \mathrm{Kj}$ er se je atiški naglas razlikoval od jonskega, je pravladal naglas prvega, prim. $\varepsilon \rho \eta \mu O$ in $\varepsilon \tau o l \mu o \mathrm{v}$ moderni grščini.
} 
naglas. »Pri izgovorjavi besede se poudarek izraža s pomočjo povečane glasnosti na poudarjenem zlogu, jasnejše kvalitete samoglasnika in rahle podaljšave. «" ${ }^{17}$

Naglasno mesto se torej načeloma ni spreminjalo. Videti je, kot da bi se ohranilo tudi načelo, da na mesto naglasa vpliva dolžina končnega samoglasnika v besedi. Toda s stališča moderne grščine to pravilo ne obstaja, ker ne obstaja ločevanje med dolgimi in kratkimi samoglasniki v nenaglašenih zlogih, zato je mesto naglasa s stališča moderne grščine znotraj zadnjih treh zlogov povsem prosto. Praviloma torej velja: »Samostalniki, ki so naglašeni na predpredzadnjem zlogu, prestavijo naglas na predzadnji zlog pred

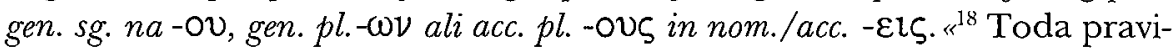
lo pozna iz že omenjenega razloga precej izjem: »Obstajajo besede, kjer se je sčasoma uveljavilo naglaševanje brez premika naglasnega mesta, na primer tov

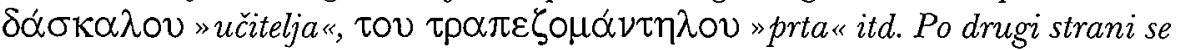
pri tourstnih samostalnikih naglas včasih prestavi tudi v nominativu plurala (O $\alpha \nu \vartheta \rho(\omega \pi \mathrm{r}) .{ }^{18}{ }^{\prime \prime}$

Sprememba tonemskega naglasa v dinamičnega je bila povezana $z$ izginjanjem razlik med dolgimi in kratkimi samoglasniki, $z$ nekaterimi samoglasniškimi spremembami in s spremembo verznega sistema.

\section{Izginjanje razlik med dolgimi in kratkimi samoglasniki}

Razlike med dolgimi in kratkimi samoglasniki so začele izginjati v zgodnji cesarski dobi. Izpričujejo jih papirusne najdbe, zlasti tiste zasebne narave; najbolj neposreden dokaz so pravopisne napake, pri katerih se omega in eta zamenjujeta $\mathrm{z}$ omikronom in epsilonom in obratno. Nekaj primerov $^{19}$ :

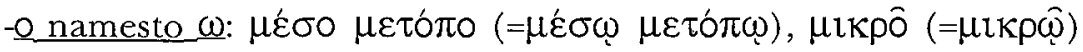

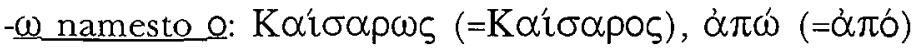

- $\underline{\text { namesto } \eta: ~} \mu \varepsilon \tau \varepsilon \dot{\varepsilon} \rho \alpha(=\mu \eta \tau \hat{\varepsilon} \rho \alpha), \pi \omega \lambda \hat{\varepsilon} \sigma \alpha \imath(=\pi \omega \lambda \hat{\eta} \sigma \alpha \mathbf{l})$

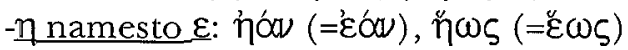

Vprašanje je, ali je izguba kvantitativnih razlik povzročila, da se je spremenil naglas, ali so se razlike med dolgimi in kratkimi samoglasniki izgubile zaradi dinamičnega naglasa. Možno bi bilo, da bi naglas ostal tonemski, čeprav razlike med dolgimi in kratkimi samoglasniki ne bi več obstajale. Toda med zgoraj navedenimi primeri je tudi nekaj takšnih, ki pričajo, da so se kvantitativne razlike izgubljale tudi v naglašenih zlogih ( $\pi \omega \lambda \hat{\varepsilon} \sigma \alpha \imath, \alpha \pi \omega, \mu \iota \kappa \rho \hat{)})$, ki naj bi torej tedaj poznali eno samo dolžino. V teh primerih bi naglas sicer lahko ostal tonemski, toda ne takšen, kot ga je imela grščina v času, ko je na vrsto naglasa vplivala dolžina samoglasnika

\footnotetext{
${ }^{17}$ Holton, str. 16. Izjema so poudarjeni odprti zlogi na koncu besede, kjer se samoglasnik ne podaljša.

is Holton, str. 24

1: Gignac, str. 242 ss
} 
in cirkumfleks na kratkem samoglasniku ni bil mogoč. Izguba razlik med dolgimi in kratkimi samoglasniki gotovo vsaj napoveduje spremembo naglasa.

Zgoraj navedene pravopisne napake se pojavljajo že v 2. st. pr. $\mathrm{Kr}$., toda v tem času jih izpričujejo samo papirusne najdbe, in so dokazljive zlasti za Egipt. Ta je bil verjetno eno izmed prvih območij, kjer se je grščina izgovarjala $z$ dinamičnim naglasom. Že v 2. st. pr. Kr. je tudi v latinščini izpričana beseda áncora $(<\not \alpha \gamma \kappa \bar{v} \rho \alpha)$ in nekoliko kasneje ídolum $\left(<\varepsilon^{\prime \prime}\right.$ $\delta \omega \lambda$ ov), kjer latinski naglas ne upošteva dolžine predzadnjega zloga v grški besedi. Možno je, da sta bili besedi prevzeti tako, kot so ju Grki v tistem času izgovarjali, torej brez razlikovanja med dolgimi in kratkimi samoglasniki v nenaglašenih zlogih. Da so so kvantitativne razlike izgubljale na različnih področjih različno hitro, priča Filostratos (Vita soph. 2, 13), ki v 2. st. po Kr. poroča, da Kapadočani ne ločujejo med dolgimi in kratkimi

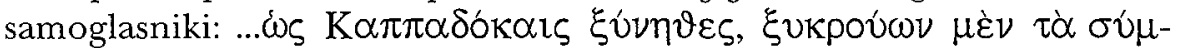

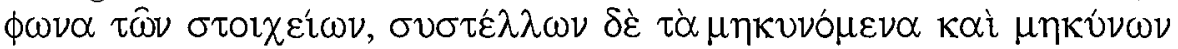

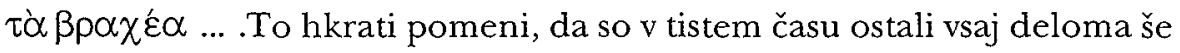
ločevali med dolgimi in kratkimi samoglasniki.

\section{Samoglasniško slabljenje, sinkopa, apokopa in afajreza}

V cesarski dobi se je okrepilo tudi samoglasniško slabljenje (ter sinkopa in apokopa) v nenaglašenih zlogih, kar je prav tako verjetno posledica dinamičnega naglasa.

Grščina v klasični dobi podobnih pojavov skoraj ni poznala. V atiščini je izpričanih le nekaj posamičnih primerov sinkope ${ }^{20}$ :

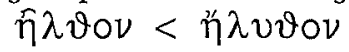

$\varepsilon \sigma \tau \alpha \mathrm{l}<$ है $\sigma \varepsilon \tau \alpha \mathrm{l}$

ö $\mu \alpha \imath<$ o"ı $\mu \alpha 1$

Tudi to je znamenje, da je bil naglas tonemski. Sinkopiranih oblik je več v cesarski dobi, na atiških napisih zlasti od 2. st. po Kr. dalje ${ }^{2 !}$.

Sinkopo najbolje izpričujejo papirusne najdbe; najpogosteje onemi samoglasnik v nenaglašenem zlogu pred likvido ali nazalom:

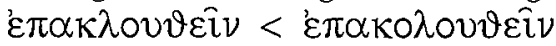

$\chi \rho \hat{\sigma \varepsilon \varepsilon}<\chi \omega \rho \eta ́ \gamma \varepsilon \imath$

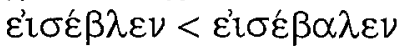

Takšni primeri se pojavljajo zlasti od 1. st. po Kr. dalje, torej nekoliko kasneje kot so se skrajšali dolgi samoglasniki v nenaglašenih zlogih.

Samoglasniško slabljenje je že zelo zgodaj poznala tesalščina; kažejo

${ }^{20}$ Sihler, str. 75. Tudi za te primere obstajajo drugačne razlage. Obliki ع̌ $\sigma \tau \alpha \iota$ in ól $\mu \alpha \mathbf{l}$ bi bili lahko atematni tvorbi, *elu pa bi bil lahko podaljšan koren od *el $\vartheta \vee \hat{\eta} \lambda$ $\vartheta 0 v$ je pripona), prim. Chantraine, str. 247, 229.

${ }^{21}$ Gignac, str. 302 ss 
ga vsi napisi, ki pa segajo šele v helenistično dobo. Toda ni jasno razmerje med naglasom in slabljenjem, saj pogosto oslabijo ali izginejo samoglasniki, ki bi bili naglašeni tako v jonsko-atiškem kot v lesboškem narečju (prim. tes. A $\pi \lambda \circ \nu \nu$ proti jon.-at.' A $\pi \delta \lambda_{\lambda} \lambda \omega \nu$ ). Slovničarji o naglasu ne poročajo, ker v tesalščini ni bilo napisane literature. Morda je bila Tesalija eno prvih področij, kjer je bil naglas dinamičen. Isto velja za Bojotijo, kjer so zaradi podobnih samoglasniških sprememb izpeljali pravopisno reformo ${ }^{22}$.

Sinkopo in apokopo v nenaglašenih zlogih pozna tudi moderna grščina:

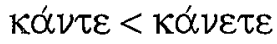

$\pi \varepsilon \rho \pi \alpha \tau \omega$ toda $\pi \varepsilon \rho^{\prime} \pi \alpha \tau o \zeta$

$\pi \alpha \rho j \tau o<\pi \alpha ́ \rho \varepsilon \tau o$

Poleg apokope in sinkope, ki jo je grščina poznala že v prejšnih obdobjih, je v zgodnjem srednjem veku prišlo še do afajreze; izginili so vsi samoglasniki na začetku besede, če niso bili naglašeni ${ }^{23}$ :

$\gamma \rho \alpha ́ \alpha \gamma \alpha \mu \varepsilon$, toda $\varepsilon \gamma p \alpha \psi \alpha$

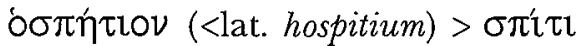

Čeprav je bil grški naglas dinamičen najmanj od konca antike dalje, samoglasniško slabljenje nikoli ni bilo zelo izrazito. Izjema je večji del narečij v severni Grčiji, kjer je samoglasniško slabljenje zelo močno ${ }^{24}$ :

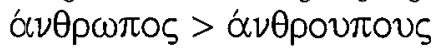

$\pi \varepsilon p^{\prime} \mu \varepsilon v \varepsilon>\pi \varepsilon \rho^{\prime}\lfloor\tau \imath \nu$

Sicer se veliko besed, na primer $\theta \alpha \dot{\lambda} \alpha \sigma \sigma \alpha, \alpha \gamma \gamma \varepsilon \lambda \circ \varsigma, \alpha \delta \dot{v} v \alpha \tau \circ, \theta \dot{\varepsilon}-$ $\alpha \tau \rho \circ$ ali $\tau \rho \alpha ́ \alpha \varepsilon \zeta \alpha$, s tega stališča ni spremenilo.

\section{Sprememba verznega sistema}

Za dinamični poudarek je značilna večja ritmična tendenca kot za tonemskega, ker se tvori tako, da se se mišična dejavnost izrazito poveča; človekov občutek za ritem pa je bistveno povezan z gibanjem. Kot pravi

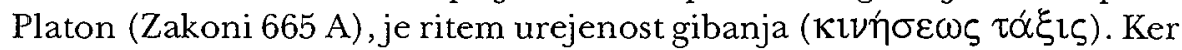
bi več zaporednih zlogov, ki bi bili izgovorjeni zelo močno, predstavljalo prevelik napor, dinamični poudarek sam po sebi teži k izmenjavanju bolj in manj poudarjenih elementov. Druga pomembna lastnost ritma in s tem verznega sistema pa je prav izmenjavanje bolj in manj poudarjenih ali pomembnih elementov.

Grški verz do cesarske dobe ne kaže znamenj, da bi naglas vplival na

${ }^{22}$ Diftong aije prešel v široki $e$ in se po novem zapisoval z $\eta$, dolgi široki $e$ je prešel v ozki $e$ in se zapisoval $z \varepsilon$, diftong $e i$ je prešel $v i$ in se zapisoval $z l$, diftong oije prešel $\mathrm{v} \ddot{u}$ in se zapisoval $\mathrm{z} v$.

${ }^{23}$ Browning, str. 63. Pogosto se je samoglasnik iz različnih razlogov vzpostavil nazaj; tako se je po analogiji s E $\lambda \lambda \eta v \varepsilon \varsigma$ obdržala oblika $E \lambda \lambda \alpha ́ \alpha \delta \alpha$.

${ }^{24}$ Browning, str. 121 
ritem, kar je je eden izmed dokazov, da je bil naglas do tedaj tonemski. Ritem je bil kvantitativen, temeljil je torej na izmenjavanju dolgih in kratkih zlogov. Kvantiteta in naglas sta bila v verzu v podobnem razmerju kot ritem in melodija.

Znamenja, da je v grščini naglas vplival na ritem, se pojavijo šele v cesarski dobi. Tak primer so Babrijeve pesmi, napisane v holijambu. Zanje je značilno, da se končajo na zaporedje naglašen-nenaglašen zlog; kvantiteto je torej nadomestil (dinamični) naglas. $V$ nekaterih primerih $\mathrm{v}$ poudarjenem delu stopice nastopajo celo (nekoč) kratki naglašeni samoglasniki. (Če je bil naglas tedaj takšen kot v grščini danes, se je samoglasnik fonetično podaljšal.) Kdaj je Babrij živel, ni jasno. Ponavadi se uvršča na konec drugega ali v tretje stoletje po $\mathrm{Kr}$.

Podobne naglasne posebnosti kažejo nekateri heksametri in parojmijaki iz približno istega časa (2. st.), za katere je značilno, da je predzadnji zlog naglašen in "kratek « ${ }^{25}$. Nonnus Panopolitanus je v kvantitativnem heksametru naglas upošteval tako, da se je izogibal naglasu na zadnjem ali predpredzadnjem zlogu v verzu; takšno naglaševanje je možno samo pri citatih iz Homerja. Največkrat je konec verza enak kot pri Babriju ${ }^{26}$.

Ti verzi niso akcentuacijski; toda prejšnji kvantitativni verz podobnih posebnosti ne kaže. Pravi akcentuacijsi verz se je razvil v približno istem času. Na prehodu iz drugega v tretje stoletje je akcentuacijski ritem značilen za pesmi Klementa iz Aleksandrije, v 4. st. pa za krščansko himno neznanega avtorja in za nekatere pesmi Gregorija Nacijanca ${ }^{27}$. Akcentuacijski verz so torej razvili krščanski pisci, ki so pisali tudi za neizobražene, za katere je bila grščina pogosto tudi tuj jezik.

Ko je nastal akcentuacijski verz, je bil naglas gotovo že dinamičen in razlike med dolgimi in kratkimi zlogi niso več obstajale, vsaj v nenaglašenih delih besede; akcentuacijski verzje bil najbolj naraven, čeprav so skozi vso bizantinsko dobo nekateri pesniki še naprej pisali tudi v kvantitativnem verznem sistemu. Ob koncu antike je bil torej grški naglas gotovo že povsod dinamičen, čeprav je vsaj na nekaterih področjih proces stekel že v zgodnji cesarski dobi.

\footnotetext{
25 Maas, str. 15

${ }^{21 j} \mathrm{Za}$ vse naštete metrične posebnosti je značilno, da ima vlogo pri ustvarjanju ritma vedno zlog, ki je naglašen $z$ (nekdanjim) akutom in nikoli, če nosi znamenje za cirkumfleks. Vzroki za to posebnosti niso znani.

${ }^{27}$ Allen, Accent and Rhytm, str. 268
} 


\section{LITERATURA}

Allen, W.S.: Accent and Rhytm, Prosodic features of Latin and Greek, Cambridge 1973.

- :Vox Graeca, The pronunciation of Classical Greek, Cambrige $1974^{2}$ Browning, R.: Medieval and Modern Greek, London 1969.

Chantraine, P.: Morphologie historique du grec, Paris $1973^{2}$.

Gignac, F. Th.: A Grammar of the Greek papyri of the Roman and Byzantine periods, Milano 1976.

Holton, D., Mackridge, P., Philippaki-Warburton, I.: Greek, A Comprehensive Grammar of the Modern Language, London 1997.

Maas, P.: Greek Metre, translated by H. Lloyd-Jones, Oxford 1962.

Schwyzer, E.: Griechische Grammatik auf der Grundlage von Karl Brugmanns Griechischer Grammatik, I Allgemeiner Teil, Lautlehre, Wortbildung, Flexion, München 1939.

Sihler, A. L.: New comparative grammar of Greek and Latin, Oxford 1995

Sturtevant, E.H.: The Pronunciation of Greek and Latin, Linguistic Society of America, $1940^{2}$. 


\section{Jerneja KAVČIČ: PROBLEMS OF ANCIENT AND MODERN GREEK ACCENT}

\section{Summary}

The basic rule, according to which the indoeuropean free accent changed in Greek, confined the acute accent within the last three syllables of the word and the circumflex within the last two ones. This is the only rule governing the position of the accent that can be considered as common Greek. In regards of the position, the modern Greek accent follows the rules of ancient Attic without basic changes.

The ancient Greek accent was tonal, but the difference between the acute and the circumflex is not clear. According to the Greek grammarians and some phonetic phenomena, the difference between the two was one of rising (acute) and rising-falling (circumflex) pitch, although the latter could also be considered as falling pitch. Another problem is presented by the third accent mark, the grave, which could indicate falling pitch or absence of accent.

The modern Greek accent is dynamic. The tonal accent disappeared gradually in a process, which was finished at least in the $4^{\mathrm{ll}}$ century AD, and accompanied by loss of vowel-lenght distinctions, by vowel weakening and vowel loss and by transformation of the Greek verse system. 